\title{
Actions of nurses and teachers in the prevention and combat of childhood obesity
}

\author{
Ações de enfermeiros e professores na prevenção e no combate à obesidade infantil
}

\section{Acciones de enfermeros y profesores en la prevención y en el combate a la obesidad infantil}

Fabiane Dias da Rosa dos Santos ${ }^{1}$, Camila Bueno Vitola ${ }^{1}$, Isabel Cristina de Oliveira Arrieira ${ }^{2}$, Maria Cristina da Silveira Chagas ${ }^{1}$, Giovana Calcagno Gomes ${ }^{1}$, Fabiani Weiss Pereira ${ }^{1}$

The objective of this study was to know how nurses and teachers contribute to prevent and combat childhood obesity. It is a qualitative study, conducted in 2012, with data collected through interviews with three nurses from a basic health unit and eight teachers from a public school in southern Brazil. Thematic analysis pointed out as factors that contribute to childhood obesity eating unhealthy foods and the families' food culture. As actions of prevention and combat there is the promotion of breast feeding, the mother's educational process and the use of recreational activities that promote children's learning about obesity. It was concluded that joint and systematic actions among nurses and teachers are important to fight childhood obesity.

Descriptors: Child; Obesity; Health Education; Child Rearing; Nursing.

Objetivou-se conhecer como enfermeiros e professores contribuem para prevenção e combate da obesidade infantil. Estudo qualitativo, realizado em 2012, com os dados coletados por entrevistas com três enfermeiros da Rede Básica e oito professores de uma escola fundamental de um município do sul do Brasil. A análise temática apontou como fatores que contribuem para a obesidade infantil a ingestão de alimentos pouco saudáveis e a cultura alimentar das famílias. Como ações de prevenção e combate o incentivo ao aleitamento materno, o processo educativo da mãe e o uso de atividades lúdicas que favoreçam a aprendizagem da criança sobre obesidade. Concluiu-se como importantes ações conjuntas e sistemáticas entre enfermeiros e professores para o enfrentamento da obesidade infantil.

Descritores: Criança; Obesidade; Educação em Saúde; Educação Infantil; Enfermagem.

El objetivo fue conocer como enfermeros y profesores contribuyen para prevención y combate a la obesidad infantil. Estudio cualitativo, realizado en 2012, con datos recolectados por entrevistas con tres enfermeros de la Red Básica y ocho profesores de una escuela primaria de un municipio del sur del Brasil. El análisis temático indicó como factores que contribuyen a la obesidad infantil el consumo de alimentos poco saludables y la cultura alimentaria de las familias. Como acciones de prevención y combate al incentivo de la lactancia materna, el proceso educativo de la madre y la utilización de actividades lúdicas que promuevan el aprendizaje del niño sobre la obesidad. Se concluye como importantes acciones conjuntas y sistemáticas entre enfermeros y profesores para enfrentamiento de la obesidad infantil.

Descriptores: Niño; Obesidad; Educación en Salud; Crianza del Niño; Enfermería.

\footnotetext{
${ }^{1}$ Universidade Federal do Rio Grande. Rio Grande, RS, Brazil.

${ }^{2}$ Universidade Católica de Pelotas. Pelotas, RS, Brazil.

Corresponding author: Maria Cristina da Silveira Chagas

Av. Portugal 397. Apto. 01. Cidade Nova - CEP: 96211-560. Rio Grande, RS, Brazil. E-mail: maria25cris@yahoo.com.br
} 


\section{Introduction}

Childhood is the ideal moment to learn good habits, since the child is seeing the world around him and developing his personality. Among these habits there is the one of eating well. Nutrition plays a fundamental role for quality of life because it contributes to physical and mental well-being.

The food and nutrition are basic elements to health promotion and protection. Nutritional status is linked to socio-cultural values, body image, social cohabitation, lifestyle, family financial situation, types of food consumed away from home, eating habits, among others ${ }^{(1)}$.

A disorder that comes with inadequate feeding is obesity, a chronic disease characterized by excessive accumulation of fat in such a proportion that it compromises health. Its most common complications are musculoskeletal changes, dyslipidemia, hypertension and diabetes mellitus. The excess of body weight is a predisposing factor for various diseases such as cardiovascular ones and metabolic syndrome, which is associated with increased morbidity and mortality ${ }^{(2)}$.

Overweight and obesity are becoming problems increasingly prevalent in both developed and developing countries, and are considered global epidemics and the most serious public health challenges of the XXI century ${ }^{(3)}$. In Canada, $21.5 \%$ of children between two and five years old are overweight, with physical and psychological consequences for them and economic consequences for society ${ }^{(4)}$. In Europe, about $20 \%$ of the children are overweight $^{(5)}$.

One in three Brazilian children between five and nine years old have weight over the percentage recommended by the World Health Organization. Out of these, $33.5 \%$ are overweight and $14.3 \%$ are obese ${ }^{(6)}$.

Obesity causes psychological effects on children leaving marks throughout their existence. It can cause difficulty of social interaction in order to avoid prejudice and discrimination. Obese children tend to eat more and more food and to remain confined to their homes as a way to assuage the anger and the anguish of not being accepted in their groups ${ }^{(7)}$.

The main causes of childhood obesity are caloric intake higher than the energy expenditure, excessive consumption of caloric foods and beverages at school, over-dedication of parents to work leading to greater supply of prepackaged foods in the family environment, the contemporary lifestyle, decreased physical activities such as using vehicles to get to school, more time at the computer and television and the genetic predisposition ${ }^{(8-9)}$.

The family is the main responsible for offering food to children and the creation of their eating habits. Healthy behaviors are rooted in childhood and consolidated throughout life. In this sense, parents should be counseled about the importance of a healthy food choice and the need to encourage their children to do physical activities, important for the prevention of childhood obesity ${ }^{(10)}$.

In 2012, more than 50,000 schools in 2,500 Brazilian cities committed to implement goals and actions of promotion, prevention, education and evaluation of the children's and adolescents' health conditions. Given the prevalence of obesity among children in Brazil and the importance of prevention of this disease, the school environment has been considered the best space for conducting a data collection about the disease and for the necessary interventions ${ }^{(11)}$.

Many students are influenced by teachers, especially the physical education ones. In this sense, the participation of the school is essential in combating childhood obesity, because it helps students understand the goals of a healthy diet and physical exercise, enabling better health ${ }^{(11)}$.

Preventing childhood obesity means decreasing rationally and cheaply the incidence of chronic diseases in the future. The school is like a big stage to enable the nutritional education of children and their families. Healthy eating is an educational content and the incorporation of good eating habits occurs since 
childhood. Investing in children's health is thinking long term, as the adult is a consequence of what he was as a child ${ }^{(12)}$.

To change this situation, the nurse should advise the family along with the children about the dangers of a sedentary lifestyle and obesity, which is considered a chronic disease of difficult control, through nursing consultations about the consequences of the disease. In addition, clarifications about what those consequences might bring to the child's future and the benefits of a change in eating habits are required, and the benefits will result subsequently in a better quality of life ${ }^{(13)}$.

Study about family support to obese children found out that parents often do not realize that their children are overweight. One way to avoid this problem is to adopt a healthy lifestyle ${ }^{(4)}$. Thus, nurses should act in the prevention of this disease with the family and the school, as this professional has an important role as an educator, promoting education, alerting parents about the hazards that obesity can cause $^{(14)}$.

Several risk factors for both overweight and obesity in childhood are identifiable during this phase $^{(15)}$. In this sense, nurses can help promote healthy habits and nutrition, in the prevention too, identifying risks and detecting obesity precociously, and they should consider the family as the center of the educational process.

It is understood that the Family Health Strategy, which hitherto focused primarily on combating childhood malnutrition, needs to integrate this context and assimilate new concepts to expand their actions with regard to childhood metabolic diseases such as obesity ${ }^{(16)}$. It is necessary for nurses to develop through health education strategies that can instruct the population about the importance of getting a better quality of life $\mathrm{e}^{(14)}$.

For the prevention, detection and treatment of obesity to be implemented early and effectively, the monitoring of children's development is essential in nursing care. In this context, the question that guided this study was: What actions to prevent and combat childhood obesity are performed by nurses and education professionals? From this question, this study aimed to identify how nurses and teachers contribute in preventing and combating childhood obesity.

\section{Method}

The research is characterized as a qualitative study, of exploratory and descriptive character. The qualitative approach works with a universe of meanings, motives, aspirations, beliefs, values and attitudes, allowing greater depth of relationships, processes and phenomena that cannot be translated through their reduction to the operationalization of variables ${ }^{(17)}$. The descriptive research addresses the description of the investigated phenomenon, allowing one to know the problems experienced ${ }^{(18)}$.

It was held in two locations: a basic unit of the Family Health Strategy and in an elementary school in a city in southern Brazil. Both sites located in the same neighborhood. The basic unit of the Family Health Strategy is comprised of three teams each formed by two nurses, a doctor, a nurse technician and six community health agents. In this place, there are eight rooms for patients' care. The school is located in the area covered by the basic unit of the Family Health Strategy. It has 45 teachers, 568 students enrolled, covering the age group from four years old to 17 years 11 months and 29 days, divided into areas and curriculum. The morning period has 268 students and the afternoon 300.

The participants of the study were three nurses and eight teachers who met the inclusion criteria: having more than two years of professional practice for teachers and more than six months for nurses. Exclusion criteria referred to the teachers and nurses who were on vacation or leave during the period of data collection. The nurses in the study had between seven and thirteen years of experience and teachers between two and eight years. 
Data collection took place in October 2012 through a single semi-structured interview with each participant. They were questioned about the actions they perform for the prevention and combat of childhood obesity. They were previously scheduled and conducted at the participants' workplace in a room which ensured the confidentiality and privacy.

The data were analyzed and interpreted by the technique of Theme Analysis ${ }^{(17)}$. This technique was implemented in three steps: Pre-analysis in which the record units that guided the analysis were identified; Exploration of material in which the data were classified and aggregated into categories and Treatment of results in which there was the interpretation of the data, correlating them with scholars of the theme.

The study subjects were identified by the letter $\mathrm{N}$ (nurses) and $\mathrm{T}$ (teachers) followed by the interview number. The research project was reviewed and approved by the Ethics Committee in Research of the Universidade Católica de Pelotas [Catholic University of Pelotas], with opinion number 111,343.

\section{Results}

The analysis generated two categories: Factors that contribute to childhood obesity and actions of prevention and combat of childhood obesity.

\section{Factors that contribute to childhood obesity}

Nurses attribute childhood obesity to eating unhealthy food by the children: the community has quite wrong eating habits, they eat too much junk food, snacks, candies, lollipops (N1) and nowadays there are many attractive foods, good things, it depends on each person's culture, it is difficult for many to join a healthy diet (N3).

They understand that eating habits are part of the families' culture not being effective to intervene only on the child, being necessary to discuss the issue with the family and the community: The thing is cultural. We must also work with the family and the community. Call the population's attention to this (N3).
Teachers also attribute childhood obesity to eating inappropriate foods, claiming to have such perception by observing the food taken by children as a snack: they bring, from what we can see, a lot of salty snacks and sandwich cookies (T1) and everything is about the snack (T2), it is during the snack time, they prefer junk food, instead of healthy foods (T8) and by the type of food they bring to school, we realize their poor $\operatorname{diet}(\mathrm{T} 6)$.

They attribute obesity to their culture and eating habits, because they recognize how difficult it is to change them. They observe through the snacks brought by children to school, what type of food they must ingest at home: the type of food that they bring to school shows the way they behave in the time to eat (T3) and during the snack time, we perceive their habits. It's hard to change habits (T4).

They blame the family for the children's eating habits, saying that the family gives in to the children's appeals, allowing regular intake of foods that should be consumed as an exception: mothers end up giving in to the children's appeals that end up eating regularly what should be an exception (T5).

In this context, they feel limited to conduct children's education into a healthy eating habit, as they would need the family's help in order to succeed to modify the children's habits: It's pointless the fact that the school provides adequate food, if they bring junk food from home. The family should work together to change the children's eating habits (T7).

\section{Prevention and combat of childhood obesity}

Reports indicate that nurses encourage breastfeeding and discuss about healthy eating habits since childcare consultations: we always start with the question of stimulus for the mommy to breastfeed exclusively. We emphasize the importance of breast milk for the child (N1), because I actually worry about it, I have always worried. There is a group of kids that came from childcare, I perform monthly anthropometric measurements and give guidance regarding healthy eating habits (N2) and guidance on a daily basis in consultations happen a lot, since all of them came for the nursing consultation before. Then we have always try to emphasize the food issue, because mothers have many questions (N3). 
They understand that mothers do not recognize obesity as a health problem, it is necessary to call their attention to this issue. When I see overweight children, I try to show their mothers, because they sometimes do not see it as a problem, that the child's health might be affected. It's necessary to show them this perspective, because only then they might take an attitude about it (N2).

During the nursing consultation when obesity or overweight are identified in a child, it is invested in the mother's educational process, planning with her a healthy diet and emphasizing the need to change the eating habits. When anthropometric data have alterations the child is taken to a doctor and to a nutritionist. During consultations when we identify an obese child we try to talk to the mother and with her plan a healthier diet, trying to change the child's eating habits (N1), the guidance to mothers during the consultation already happens, but when a child is identified as obese or overweight we try to emphasize the importance of the food issue (N3), When we identify more severe cases of obesity children are taken to a nutritionist. I do the anthropometric measurements and if they have alterations, I take the child to a doctor and to a nutritionist of the network (N2).

They carry out integrated actions with the school in order to prevent and combat obesity. They think it is important that educational activities in schools are conducted by a multidisciplinary team since they can bring better results in quality of life, especially of children who have childhood obesity: we do educational activities in schools and immunization campaigns. Actions are integrated with the teachers (N1).

Teachers talk to children and their families about the importance of good nutrition, to bring healthy snacks and about their hands hygiene. I think that by talking to them about what they bring for snack (T1) with educational activities, showing the importance of good nutrition (T2) promoting health through habits that we should keep in our everyday life, for example, washing hands (T4) I try to ask mothers to send healthier foods to school, avoiding the greasy foods (T5) and clarification to students, talk about healthy eating (T6).

There are teachers, however, who do not feel prepared to conduct health education related to the obesity theme: I try to talk about it in class, even not feeling prepared (T3).

There are teachers who seek to guide students by providing them with content about good nutrition: the most appropriate management is to guide students. I believe I do that through the content covered in class related to good nutrition, guiding and encouraging healthy eating, but always respecting the differences (T7).

They believe that with the use of recreational activities such as storytelling, using characters children learn best, favoring their interaction and learning: through a playful way, like stories, we create a character, then they can directly interact with us and learn more about what a good diet is, I also do the junk food day, then they can eat what they want, but with an appointed day, in the other days, only healthy snacks (T8).

\section{Discussion}

Concerning the factors that contribute to childhood obesity, both nurses and teachers attributed it to the intake of unhealthy foods by children. They believe that the food culture of the family governs children's feeding behavior. Thus, the intensity of parental involvement in the implementation of techniques of behavior change is an important issue in the effectiveness of weight management interventions in children in long-term ${ }^{(5)}$.

A study about the factors related to obesity in school children in Iran conducted in eight primary schools of Rasht with 320 students indicated that the frequency of meals and the type of food eaten was significant for high body mass index in children ${ }^{(19)}$. In this study, when teachers observed the snacks brought from home by the children, they felt that children were eating inappropriate foods that contributed to their weight gain. Thus, it is urgent to implement measures for the prevention of childhood obesity such as encouraging regular physical exercise and the realization of a healthy $\operatorname{diet}^{(16)}$. 
The family is responsible for children's eating habits and often gives in to their appeals, allowing regular intake of foods that should be consumed as an exception. A European study about the role of parents in feeding children identified that the intensity of their involvement in implementing interventions for weight control is effective in the prevention of childhood obesity in long term. Thus, their participation is important for the promotion of child health and for the constitution of a healthy lifestyle ${ }^{(5)}$.

As for the prevention and combat of childhood obesity it was identified that promotion of exclusive breastfeeding is presented as a strategy. A study on the relationship between breastfeeding and childhood obesity found out that children who had an early introduction of complementary foods had an average body mass index significantly higher than those who received exclusive breastfeeding(20). Another study compared breastfed and non-breastfed infants and found a $15 \%$ decrease in the likelihood of overweight in children who were exclusively breastfed, associating the early introduction of solid foods with excess weight during childhood(15).

Given the high rates of obesity and the consequences that it causes, health professionals/ nurses should carry out early diagnosis and implement prevention and control of this disease. For children the resolution of this problem must include information and advice on family eating habits and daily physical activities ${ }^{(16)}$. In this context, according to the advocating of the Programa Saúde e Prevenção na Escola [Health and Prevention in Schools Program], it is necessary an integration between schools and health services through a joint action or by the school in isolation so that there is the conduction of strategies for improvements in relationship to childhood obesity. Nurses' role in child care is important because in the basic health unit they have working tools that help identify and monitor the growth of children, namely: measurement of weight and height, filling out the children's vaccination card, making their growth curve and calculating the expected weight gain for their age ${ }^{(16)}$.

The identification of children at risk of obesity provides health professionals/nurses the opportunity for early intervention, with the aim of limiting the progression of abnormal weight gain ${ }^{(19)}$. From the moment they identify obesity, it is important to monitor it together with other professionals, especially nutritionists ${ }^{(20)}$.

If the wrong eating habits and sedentary lifestyles are constituted as the main factors that lead to childhood obesity, it can be considered that the lack of information and proper education influence this process. When families do not have the necessary information to correct these factors, school and health services are presented as the main vehicles of information for children, and they should play their role to educate in the broadest sense ${ }^{(13)}$.

Educational activities in schools and health services can bring better results in decreasing childhood obesity. A study that aimed to analyze, from the perspective of nurses, the possibilities of an action of professionals at schools, aimed at the prevention and control of childhood obesity found that, for these, the main strategy/methodology to be adopted would be to conduct educational talks, involving parents, teachers and students, acting in an integrated way ${ }^{(11)}$.

Besides these, other strategies can be undertaken to improve the process of absorbing information such as the use of interactive activities with students and teachers on issues related to healthy eating and physical activities. They also mentioned the importance of the use and exploitation of artistic media such as music, films and educational theater improving the absorption of knowledge about the subject ${ }^{(16)}$.

\section{Final Considerations}

Among the study subjects, it can be observed that nurses cited as factors contributing to obesity 
in children the intake of unhealthy food and culture of families, not being effective an intervention only with the children. While teachers attribute childhood obesity to eating inappropriate food consumption observed by them during children's breaks from classes. Both professionals point difficulties in changing the children's habits due to their family practices.

Among the actions to prevent and combat childhood obesity nurses discuss healthy eating habits with families. They invest in the families' educational process, planning a healthy diet for children, emphasizing the need to change their eating habits in the family context. Thus, it is important to take children to other professionals in their specialties such as doctors, nutritionists and psychologists.

The teachers talk about good dietary practices instructing children and their families about the importance of good nutrition, about preparing healthy snacks to bring to school, including hygiene measures especially hand washing. The use of recreational activities such as storytelling, using characters, promotes children's learning about obesity.

Nurses and teachers showed themselves as facilitators of the family's educational process about the importance of healthy eating for children and performing regular physical activities and the prevention and combat of childhood obesity.

Systematic and joint actions among health and education professionals, involving families and the community, assists in fighting childhood obesity, promoting quality of life.

\section{Collaborations}

Santos FDR, Vitola CB and Arrieira ICO contributed to the conception, organization, analysis and interpretation of data and drafting of the article. Chagas MCS, Pereira FW and Gomes GC contributed in the writing of the article, assisting in its formulation with critical and constructive reviews at all stages.

\section{References}

1. Coutinho NMP, Valões EM, Lacerda NC, Menezes DN. Avaliação nutricional e consumo de alimentos entre adolescentes de risco. Rev Rene. 2007; 8(3):9-16.

2. Pimentel GD. O papel-chave na regulação metabólica e controle da ingestão alimentar: revisão. Nutrire. 2009; 34(1):159-73.

3. Soltani PR, Ghanbari A, Rad AH. Obesity related factors in school-aged children. Iran J Nurs Midwifery Res. 2013; 18(3):175-9.

4. Lemelin L, Gallagher F, Haggerty J. Supporting parents of preschool children in adopting a healthy lifestyle. BMC Nurs. 2012; 11(1):12.

5. Van der Kruk JJ, Kortekaas F, Lucas C, JagerWittenaar H. Obesity: a systematic review on parental involvement in long-term European childhood weight control interventions with a nutritional focus. Obes Rev. 2013; 14(9):745-60.

6. Ministério do Planejamento, Orçamento e Gestão (BR). Instituto Brasileiro de Geografia e Estatística. Pesquisa de Orçamentos Familiares 2008 - 2009: Antropometria, estado nutricional de crianças, adlescentes e adultos no Brasil. Brasília: IBGE; 2010.

7. Mishima FKT, Barbieri V. O brincar criativo e a obesidade infantil. Estud Psicol. 2009; 14(3):24955.

8. Bouchard C. Childhood obesity: are genetic differences involved? Am J Clin Nutr. 2009; 89(5):1494-501.

9. Marchi-Alves LM, Yagi CM, Rodrigues CS, Mazzo A, Rangel EML, Girão FB. Obesidade infantil ontem e hoje: importância da avaliação antropométrica pelo enfermeiro. Esc Anna Nery. 2011; 15(2):23844.

10. Costa CD, Ferreira MG, Amaral R. Obesidade infantil e juvenil. Acta Med Port. 2010; 23(3):37984.

11. Araújo RA, Brito AA, Silva FM. 0 papel da educação física escolar diante da epidemia da obesidade em crianças e adolescentes. Educ Fís Rev. 2010; $4(2): 1-9$. 
12. Frota MA, Maia JA, Pereira AS, Nobre CS, Vieira LJES. Reflexão sobre políticas públicas e estratégias na saúde integral da criança. Enferm Foco. 2010; 1(3):129-32.

13. Silva RM, Koopmans FF, Sá RCB, Paulin EFR. Intervenções de enfermagem junto à família na prevenção da obesidade infantil. Cad Pesq Ext. 2010; 1(1):57-62.

14. Lugão MAS, Ferreira TVS, Aguiar OV, André KM. A importância da atuação do enfermeiro na prevenção da obesidade infantil. Rev Pesq Cuid Fundam. 2010; 2(3):976-88.

15. Weng SF, Redsell SA, Swift JA, Yang M, Glazebrook CP. Systematic review and meta-analyses of risk factors for childhood overweight identifiable during infancy. Arch Dis Child. 2012; 97(12):101926.
16. Araújo SNM, Luz MHBA, Rocha SS, Silva GRF, Duarte MR, Sandes NM. Obesidade infantil: conhecimentos e práticas de enfermeiros da Atenção Básica. Enferm Foco. 2012; 3(3):139-42.

17. Minayo MCS, organizadora. Pesquisa social: teoria, método e criatividade. 29a ed. Petrópolis (RJ): Vozes; 2010.

18. Triviños ANS. Introdução à pesquisa em ciências sociais: a pesquisa qualitativa em educação. São Paulo: Atlas; 2009.

19. Soltani PR, Ghanbari A, Rad AH. Obesity related factors in school-aged children. Iran J Nurs Midwifery Res. 2013; 18(3):175-9.

20. Vafa M, Moslehi N, Afshari S, Hossini A. Eshraghian M. Relationship between breastfeeding and obesity in childhood. J Health Popul Nutr. 2012; 30(3):303-10. 